\title{
Characteristics of Emergency Department Visits at King Abdulaziz University Hospital: A One Year Analysis
}

\author{
Jameel T. Abualenain ${ }^{1,2,3}$, MD, MPH, FACEP, FAAEM, CHSE \\ 'Department of Emergency Medicine, Faculty of Medicine \\ King Abdulaziz University, Jeddah, Saudi Arabia \\ ${ }^{2}$ King Abdulaziz University Hospital, Jeddah, Saudi Arabia \\ ${ }^{3}$ Department of Emergency Medicine, George Washington University, Washington DC, USA
}

\section{Correspondence}

Dr. Jameel T. Abualenain

P.O. Box 80215, Jeddah 21589

Saudi Arabia

e.M: abualenain@kau.edu.sa

\section{Submission: $\quad 06$ Feb 2018}

Accepted: $\quad 26$ Feb 2018

\section{Citation}

Abualenain JT. Characteristics of emergency department visits at King Abdulaziz University Hospital: a one year analysis. JKAU Med Sci 2018; 25 (1): 1-7. DOl: 10.4197/Med. 25.1.1

\begin{abstract}
This study seeks to report the frequencies of the Emergency Department visits at King Abdulaziz University Hospital, as well as an analysis of its operational parameters. This is a retrospective analysis of all emergency visits over one year. In 2017, 69,522 patients were triaged, $62.55 \%$ adults, $20.12 \%$ pediatrics, and $17.33 \%$ OB/GYN. Ineligible patients (lower acuity stable non-Saudi patients who hold health insurance through their sponsors) were $12.84 \%$ of triaged patients, they were advised to go to another hospital. Females were $57.11 \%$, and $40.92 \%$ were between 24 and 43 years, $18.49 \%$ younger than 14 years, and $9.22 \%$ older than 64 years. Saudi patients were $64.76 \%$. Only $0.40 \%$ arrived by ambulance. Full management was provided for $73.83 \%$ of registered patients, whereas $26.17 \%$ left the waiting room after triage and initial evaluation by a physician without being treated due to bed unavailability; $97.22 \%$ were lower acuity and stable. Admission rates were $23.44 \%$. The overall emergency department mortality rate was $0.52 \%$, and death on arrival rate was $0.25 \%$. Most registered patients ( $86.18 \%$ ) were lower acuity and stable. All cases in which the patient needed resuscitation were treated immediately. Emergency department use by patients with low acuity conditions that are potentially treatable in other settings must be addressed.
\end{abstract}

\section{Keywords}

Emergency department; Crowding; Quality

\section{Introduction}

$N$ owadays, emergency departments (EDs) are the safety net for a large patient population that fails to get to the health care system in a timely manner for either accessibility or financial reasons such as poor availability of regular primary care and other urgent care settings, or suboptimal management of chronic illness. This issue is occurring in governmental and private EDs at the national and international levels. Emergency departments are overcrowded with large numbers of unnecessary emergency visits that can be dealt with in non-emergency settings such as outpatient clinics, primary care facilities, family medicine offices, urgent 
care locations, or at home. These ED visits place a huge burden on any health care system and drain ED resources significantly ${ }^{[1-4]}$.

In Saudi Arabia, the government has a very clear and strict law which states that any patient presenting to any ED with a life- or limb-threatening condition is to be attended to immediately, regardless of any other factors used to determine eligibility. However, other less urgent or non-emergent conditions vary dramatically in terms of acceptance in EDs based on each facility's regulations. Even governmental institutions vary dramatically in their eligibility criteria, which makes ED populations vary significantly based on the institution's rules.

The ED at King Abdulaziz University Hospital (KAUH) went through major transformations over the past couple of years. The academic staff grew significantly, board-certified emergency medicine (EM) physicians were hired, an EM residency training program was established, more than 15 scholar physicians were sent abroad to become EM board-certified, and a complete high-quality renovation with updated state-of-the-art equipment took place. This is the first study that reports the characteristics of the ED visits at KAUH over a oneyear period. The aim is to report the frequencies of the total ED visits for each ED section, as well as provide an analysis of the demographics, acuity of presentations, and dispositions of all ED visits per ED section. This will be a valuable step toward understanding the current situation and how to move forward in improving ED crowding and providing a high quality of emergency care.

\section{Materials and Methods}

This was a retrospective analysis of all ED visits at $\mathrm{KAUH}$ over a one-year period, from 1 January to 31 December 2017. This study was conducted at the ED of KAUH, an academic tertiary care center in Jeddah, Saudi Arabia, with 845 hospital beds. This study was approved by KAU's research ethics committee. The ED has 71 ED beds and receives about 66,000 visits per year. It has three sections: adult, pediatrics, and obstetrics and gynecology (OB/GYN). The adult ED has 44 beds and is staffed by EM consultants, specialists, and nurses. The ED also has a pediatric EM (PEM) section that has six beds (another seven beds will open soon-they are closed due to PEM nursing shortage) with its own providers and nursing coverage; this is also the case for the $\mathrm{OB} /$ GYN section, but that section only has four beds. All patients, regardless of their age, who were triaged and then registered in KAUH's Health Information System (HIS) (Phoenix, Al Anaiah International Company Ltd, Jeddah KSA) were included in the study. The exclusions were lower acuity and stable patients' ineligible to register in KAUH ED. All patients who arrive to the ED are triaged utilizing the Canadian Triage and Acuity Scale (CTAS), a five-level triage acuity scale, corresponding to 1 (Resuscitation), 2 (Emergent), 3 (Urgent), 4 (Less Urgent), and 5 (Non-Urgent). During registration, patients are assigned in Phoenix to their respective ED section with the determined CTAS level (1-5). All CTAS 1-2 patients get registered with no restrictions and regardless of their nationality. However; CTAS 3-5 patients are registered based on whether they are eligible or ineligible patients. Eligible patients are citizens of Saudi Arabia/Gulf region and university/ hospital staff including their dependents regardless of their nationality. Additionally, exemptions are made for the following to be eligible for registration: non-Saudis who are sponsored by individuals (not companies), some infectious diseases (assigned by Ministry of Health), active cancer patients on chemotherapy, and some nationalities facing crisis in their homeland (decided by the government). Ineligible patients (CTAS 3-5 patients) are non-Saudis who hold health insurance through their sponsors (companies, agencies, etc.), they do not get registered and are advised to seek medical care in the private sector or governmental hospitals that have private track.

Data were extracted from Phoenix as independent visits (episodes). Each episode contains the patient's age, gender, triage level, nationality, eligibility, ED section, arrival mode, and disposition. Descriptive statistics, including number and percentage (\%), were collated. Data were analyzed using Microsoft Excel 2016 (Microsoft Corporation, Redmond, WA USA).

\section{Results}

In 2017, KAU ED triaged 69,522 patients in total, which includes adults (62.55\%), pediatrics $(20.12 \%)$, and OB/GYN (17.33\%). Approximately $12.84 \%$ of the triaged patients were ineligible, did not register, and were advised to seek care in other hospitals; all these patients were lower acuity (CTAS 3-5). The unregistered patients varied from $1.73 \%$ to $22.36 \%$ based on the ED section, with OB/GYN being the least and pediatrics the most. Pediatrics had the largest percentage of ineligible patients (about one-fifth of their triage patients) per section compared to adult and OB/GYN 
sections, however; the number on average does not exceed three patients per eight hours shift. This is less than the adult section which receives on average about five ineligible patients per eight hour shift. Of the 60,595 registered patients, $73.83 \%$ were placed on an ED bed and received full management. The other $26.17 \%$ stayed in the waiting room, were seen and evaluated by emergency physicians, but were not placed on an ED bed nor received management due to full occupancy of all ED beds (except resuscitation beds). Table 1 shows the total ED visits and per section with details about patients who were treated or left the waiting room after triage and initial evaluation by a physician without being treated (LWBT). Most of the LWBT comes from the adult ED section (72.63\%), followed by the pediatrics (22.49\%) and only $4.88 \%$ from the OB/GYN section.

In terms of the demographics of the patients who were registered, $57.11 \%$ were female, $40.92 \%$ of patients were between 24 and 43 years, $18.49 \%$ were younger than 14 years (pediatrics), and $9.22 \%$ were older than 64 years. Saudi-registered patients comprised $64.76 \%$. Only $0.40 \%$ of patients arrived by ambulance; the rest arrived by private vehicle. Each ED section differed in these percentages, as shown in Table 2 .

In terms of dispositions (outcomes), the admission rate for all ED patients was $23.44 \% ; 17.98 \%$ belonged to the adult section, as compared to $26.70 \%$ and $34.28 \%$

Table 1. All emergency department visits during 2017.

\begin{tabular}{|c|c|c|c|c|c|c|c|c|c|c|c|c|}
\hline & \multicolumn{9}{|c|}{ Emergency Department Sections } & \multirow{2}{*}{\multicolumn{3}{|c|}{$\begin{array}{c}\text { All ED } \\
\text { Total }\end{array}$}} \\
\hline & \multicolumn{3}{|c|}{ Adult } & \multicolumn{3}{|c|}{ Pediatrics } & \multicolumn{3}{|c|}{ OB/GYN } & & & \\
\hline & $\mathbf{N}$ & $\%$ & $\%^{*}$ & $\mathbf{N}$ & $\%$ & $\%^{*}$ & $\mathbf{N}$ & $\%$ & $\%^{*}$ & $\mathbf{N}$ & $\%$ & $\%^{*}$ \\
\hline Triaged Patients & 43,486 & - & $62.55 \%$ & 13,990 & - & $20.12 \%$ & 12,046 & - & $17.33 \%$ & 69,522 & - & $100.00 \%$ \\
\hline Registered Patients & 37,895 & $87.14 \%$ & $62.54 \%$ & 10,862 & $77.64 \%$ & $17.93 \%$ & 11,838 & $98.27 \%$ & $19.54 \%$ & 60,595 & $87.16 \%$ & $100.00 \%$ \\
\hline Treated in ED & 26,379 & $69.61 \%$ & $58.96 \%$ & 7,297 & $67.18 \%$ & $16.31 \%$ & 11,064 & $93.46 \%$ & $24.73 \%$ & 44,740 & $73.83 \%$ & $100.00 \%$ \\
\hline LWBT $^{\dagger}$ & 11,516 & $30.39 \%$ & $72.63 \%$ & 3,565 & $32.82 \%$ & $22.49 \%$ & 774 & $6.54 \%$ & $4.88 \%$ & 15,855 & $26.17 \%$ & $100.00 \%$ \\
\hline
\end{tabular}

ED: Emergency Department; OB/GYN: Obstetrics and gynecology

"Percentage from the total emergency department visits for each section

¿ LWBT: Left the waiting room after triage and initial evaluation by a physician without being treated

Table 2. Characteristics of all emergency department visits over the study period.

\begin{tabular}{|c|c|c|c|c|c|c|c|c|}
\hline & \multicolumn{6}{|c|}{ Emergency Department Sections } & \multirow{2}{*}{\multicolumn{2}{|c|}{$\begin{array}{l}\text { All ED } \\
\text { Total }\end{array}$}} \\
\hline & \multicolumn{2}{|c|}{ Adult } & \multicolumn{2}{|c|}{ Pediatrics } & \multicolumn{2}{|c|}{ OB/GYN } & & \\
\hline & N & $\%$ & $\mathbf{N}$ & $\%$ & N & $\%$ & N & $\%$ \\
\hline \multicolumn{9}{|l|}{ Age } \\
\hline$<1$ & & & 3185 & $28.44 \%$ & & & 3185 & $5.26 \%$ \\
\hline $1-6$ & & & 5344 & $47.71 \%$ & & & 5344 & $8.82 \%$ \\
\hline $7-13$ & & & 2671 & $23.85 \%$ & & & 2671 & $4.41 \%$ \\
\hline $14-23$ & 6165 & $16.41 \%$ & & & 2147 & $18.14 \%$ & 8312 & $13.71 \%$ \\
\hline $24-33$ & 9290 & $24.73 \%$ & & & 6275 & $53.01 \%$ & 15565 & $25.68 \%$ \\
\hline $34-43$ & 6350 & $16.90 \%$ & & & 2887 & $24.39 \%$ & 9237 & $15.24 \%$ \\
\hline $44-53$ & 5272 & $14.03 \%$ & & & 362 & $3.06 \%$ & 5634 & $9.30 \%$ \\
\hline $54-63$ & 4955 & $13.19 \%$ & & & 118 & $1.00 \%$ & 5073 & $8.37 \%$ \\
\hline$>64$ & 5537 & $14.74 \%$ & & & 49 & $0.41 \%$ & 5586 & $9.22 \%$ \\
\hline \multicolumn{9}{|l|}{ Gender } \\
\hline Female & 18,060 & $47.66 \%$ & 4,710 & $43.36 \%$ & 11,838 & $100.00 \%$ & 34,608 & $57.11 \%$ \\
\hline Male & 19,835 & $52.34 \%$ & 6,152 & $56.64 \%$ & NA & - & 25,987 & $42.89 \%$ \\
\hline \multicolumn{9}{|l|}{ Nationality } \\
\hline Saudi & 23,715 & $63.12 \%$ & 7,119 & $63.56 \%$ & 8,408 & $71.03 \%$ & 39,242 & $64.76 \%$ \\
\hline 0thers & 14,180 & $37.74 \%$ & 3,743 & $33.42 \%$ & 3,430 & $28.97 \%$ & 21,353 & $35.24 \%$ \\
\hline \multicolumn{9}{|l|}{ Mode of Arrival } \\
\hline Ambulance & 186 & $0.50 \%$ & 34 & $0.30 \%$ & 28 & $0.20 \%$ & 247 & $0.40 \%$ \\
\hline $\begin{array}{l}\text { Others (Walk-in or } \\
\text { Vehicle) }\end{array}$ & 37,709 & $99.50 \%$ & 10,828 & $99.70 \%$ & 11,810 & $99.80 \%$ & 60,348 & $99.60 \%$ \\
\hline
\end{tabular}

ED: Emergency Department; OB/GYN: Obstetrics and Gynecology 
for pediatrics and $\mathrm{OB} / \mathrm{GYN}$, respectively. The overall $\mathrm{ED}$ mortality rate was $0.52 \%$, and death on arrival (DOA) was $0.25 \%$. There was very little missing data $(0.14 \%)$. Table 3 shows detailed dispositions for all ED patients, by section, over the study period.

To better understand the patient population visiting KAU ED, further stratifications of patients based on their CTAS triage level as well as registered, treated, and LWBT categories for each ED section was done (Table 4). About $86.18 \%$ of registered patients were lower acuity (CTAS 3-5), not resuscitation or emergent cases. Pediatrics had the highest percentage of treated critical patients (24.41\%), followed by adults (19.32\%), and only $9.52 \%$ for OB/GYN. For LWBT patients, $97.22 \%$ of cases were lower acuity cases (CTAS 3-5). All cases which needed resuscitation (CTAS 1) were treated immediately; the $0.04 \%$ CTAS 1 cases were related to registration errors or section misplacements.

\section{Discussion}

This study sheds light on the capacity and characteristics of a major ED in the western region in Saudi Arabia. It is the first detailed report that presents one-year ED data to the public. From the general overview of the report, it is clear that KAU ED suffers major crowding challenges, which is reflected in the large number of

Table 3. Dispositions (outcomes) of all treated emergency department patients during 2017.

\begin{tabular}{|c|c|c|c|c|c|c|c|c|}
\hline & \multicolumn{6}{|c|}{ Emergency Department Sections } & \multirow{2}{*}{\multicolumn{2}{|c|}{$\begin{array}{l}\text { All ED } \\
\text { Total } \\
\end{array}$}} \\
\hline \multirow{3}{*}{$\begin{array}{l}\text { Treated in ED } \\
\text { Disposition }\end{array}$} & \multicolumn{2}{|c|}{ Adult } & \multicolumn{2}{|c|}{ Pediatrics } & \multicolumn{2}{|c|}{ OB/GYN } & & \\
\hline & & & & & & & \multicolumn{2}{|c|}{44,740} \\
\hline & $\mathbf{N}$ & $\%$ & $\mathbf{N}$ & $\%$ & $\mathrm{~N}$ & $\%$ & $\mathrm{~N}$ & $\%$ \\
\hline Admissions & 4,744 & $17.98 \%$ & 1,948 & $26.70 \%$ & 3793 & $34.28 \%$ & 10,485 & $23.44 \%$ \\
\hline Discharges & 20,367 & $77.21 \%$ & 5,056 & $69.29 \%$ & 6,889 & $62.27 \%$ & 32,312 & $72.22 \%$ \\
\hline Against Medical Advice & 907 & $3.44 \%$ & 255 & $3.49 \%$ & 376 & $3.40 \%$ & 1,538 & $3.44 \%$ \\
\hline Mortality & 221 & $0.84 \%$ & 9 & $0.12 \%$ & 3 & $0.03 \%$ & 233 & $0.52 \%$ \\
\hline Death on Arrival & 84 & $0.32 \%$ & 27 & $0.37 \%$ & 0 & $0.00 \%$ & 111 & $0.25 \%$ \\
\hline Missing Data & 56 & $0.21 \%$ & 2 & $0.03 \%$ & 3 & $0.03 \%$ & 61 & $0.14 \%$ \\
\hline
\end{tabular}

ED: Emergency Department; OB/GYN: Obstetrics and Gynecology

Table 4. All emergency department visits' distribution according to The Canadian Triage \& Acuity Scale.

\begin{tabular}{|c|c|c|c|c|c|c|c|c|}
\hline & \multicolumn{6}{|c|}{ Emergency Department Sections } & \multirow{2}{*}{\multicolumn{2}{|c|}{$\begin{array}{c}\text { All ED } \\
\text { Total }\end{array}$}} \\
\hline & \multicolumn{2}{|c|}{ Adult } & \multicolumn{2}{|c|}{ Pediatrics } & \multicolumn{2}{|c|}{ OB/GYN } & & \\
\hline & $\mathbf{N}$ & $\%$ & $\mathbf{N}$ & $\%$ & $\mathbf{N}$ & $\%$ & $\mathbf{N}$ & $\%$ \\
\hline Priority & \multicolumn{8}{|c|}{ Registered Patients } \\
\hline 1 & 387 & $1.02 \%$ & 242 & $2.23 \%$ & 5 & $0.04 \%$ & 634 & $1.05 \%$ \\
\hline 2 & 5,003 & $13.20 \%$ & 1,682 & $15.49 \%$ & 1,054 & $8.90 \%$ & 7,739 & $12.77 \%$ \\
\hline 3 & 13,593 & $35.87 \%$ & 6,841 & $62.98 \%$ & 9,608 & $81.16 \%$ & 30,042 & $49.58 \%$ \\
\hline 4 & 17,928 & $47.31 \%$ & 2,061 & $18.97 \%$ & 1,135 & $9.59 \%$ & 21,124 & $34.86 \%$ \\
\hline 5 & 984 & $2.60 \%$ & 36 & $0.33 \%$ & 36 & $0.30 \%$ & 1,056 & $1.74 \%$ \\
\hline Total & 37,895 & $100.00 \%$ & 10,862 & $100.00 \%$ & 11,838 & $100.00 \%$ & 60,595 & $100.00 \%$ \\
\hline Priority & \multicolumn{8}{|c|}{ Treated Patients } \\
\hline 1 & 386 & $1.46 \%$ & 237 & $3.25 \%$ & 5 & $0.05 \%$ & 628 & $1.40 \%$ \\
\hline 2 & 4,712 & $17.86 \%$ & 1,544 & $21.16 \%$ & 1,048 & $9.47 \%$ & 7,304 & $16.33 \%$ \\
\hline 3 & 8,173 & $30.98 \%$ & 4,311 & $59.08 \%$ & 8,962 & $81.00 \%$ & 21,446 & $47.93 \%$ \\
\hline 4 & 12,436 & $47.14 \%$ & 1,190 & $16.31 \%$ & 1,017 & $9.19 \%$ & 14,643 & $32.73 \%$ \\
\hline 5 & 672 & $2.55 \%$ & 15 & $0.21 \%$ & 32 & $0.29 \%$ & 719 & $1.61 \%$ \\
\hline Total & 26,379 & $100.00 \%$ & 7,297 & $100.00 \%$ & 11,064 & $100.00 \%$ & 44,740 & $100.00 \%$ \\
\hline Priority & \multicolumn{8}{|c|}{ LWBT Patients } \\
\hline 1 & 1 & $0.01 \%$ & 5 & $0.14 \%$ & 0 & $0.00 \%$ & 6 & $0.04 \%$ \\
\hline 2 & 291 & $2.53 \%$ & 138 & $3.87 \%$ & 6 & $0.78 \%$ & 435 & $2.74 \%$ \\
\hline 3 & 5,420 & $47.06 \%$ & 2,530 & $70.97 \%$ & 646 & $83.46 \%$ & 8,596 & $54.22 \%$ \\
\hline 4 & 5,492 & $47.69 \%$ & 871 & $24.43 \%$ & 118 & $15.25 \%$ & 6,481 & $40.88 \%$ \\
\hline 5 & 312 & $2.71 \%$ & 21 & $0.59 \%$ & 4 & $0.52 \%$ & 337 & $2.13 \%$ \\
\hline Total & 11,516 & $100.00 \%$ & 3,565 & $100.00 \%$ & 774 & $100.00 \%$ & 15,855 & $100.00 \%$ \\
\hline
\end{tabular}

ED: Emergency Department; OB/GYN: Obstetrics and Gynecology; LWBT: Left the waiting room after triage and initial evaluation by a physician without being treated 
LWBT, especially in the adults and pediatrics sections. Emergency department crowding is multifactorial and could be the result of problems in any of the following: input, throughput, or output ${ }^{[7]}$. The resulting long wait time is a worldwide challenge that is associated with bad outcomes and compromise in the quality of care ${ }^{[1-}$ ${ }^{6}$. King Abdulaziz University ED crowding is caused more by the prolonged ED boarding of admitted patients. Specifically, this is more likely a downstream challenge rather than an ED problem.

Broad population is being served by KAU ED from all age groups (including OB/GYN) since it is committed to provide full service to all KAU staff and their dependents. In addition, it is a tertiary care center that gets referrals from different regions. The follow-up of these cases when complications occur places an extra load on the ED in addition to the expected population. The aforementioned factors play a major role in the crowding experienced in KAUH ED. The OB/GYN ED section does not suffer the same challenges regarding LWBT given the nature of its presentations and the high turnover time.

One-third of all ED visits were by non-Saudis. The current Saudi regulations mandate that all non-Saudis (except individual sponsorship) must be covered by any type of health insurance before completion of their legal documentation. Hence, the expectation is that non-Saudis would receive their care in the private sector. However, this high number in a governmental institution is explained by the fact that KAUH ED covers all of its employees regardless of the nationalities; also, all CTAS 1-2 patients are registered.

One interesting finding was the arrival mode to the $E D$, where only $0.40 \%$ of patients used an ambulance to come to the ED. This is probably related to the underdeveloped emergency medical services in the city. In addition, further studies or surveys need to be done to understand this abnormally low number compared to the United States $(14 \%)^{[8]}$.

All patients with life-threatening conditions (CTAS 1 and 2) were registered without restrictions and transferred to ED beds immediately. Some minor delays occurred for patients with emergent but nonlife-threatening issues (CTAS 2) if immediate bedding was not available, but they were resolved in an accelerated way most of the time. Handling emergency and life-threatening cases (CTAS 1-2) does not seem to represent a major concern in terms of bed placement or management. Most of the LWBT patients (97.22\%) were non-emergent cases (CTAS 3-5), which brings up a very important question about the appropriate utilization of the ED by the population and reasons behind such culture. Most of these cases can be managed through primary health care, staff clinics, family physicians, urgent care centers, or even home health care services.

Left without being seen (LWBS) patients is a wellknown and frequently used indicator in ED operations. The reported rate from most reports globally usually ranges from $1-3 \%$, which is considered the benchmark. These patients do not get anything by triage. In our ED it is extremely difficult to obtain an accurate LWBS rate because it highly mixed with LWBT rate. Left the waiting room after triage and initial evaluation by a physician without being treated patients received initial evaluation by an emergency physician, which includes obtaining brief history and performing focused physical exam which might take place in the triage room or any available bed in the waiting room. Left without being seen patients are included in the LWBT and roughly represents a small fraction (no specific number available). Almost all CTAS 3 are seen by a physician after triage, this is not the case for some CTAS 4-5 where patients might leave the ED after realizing the long waiting time. It would be hard to report any accurate rate for this category. It is important to mention that all triaged patients who are waiting to be seen can request to see the emergency physician on duty. This does not mean that the physician will be able to accommodate them on an ED bed or recliner for complete management because it depends on the level of crowdedness.

Limitations of this study include the generalizability of its findings since it has its own unique population and settings. Also, a retrospective records review carries the possibility of missing data or wrong entries. In addition, this study should be followed by multiple studies in the near future that address the other ED operation factors such as information about the waiting time for each CTAS level, ED length of stay, decision time, diagnoses, boarding time, and ED occupancy rates.

\section{Conclusion}

King Abdulaziz University Hospital Emergency Department plays a major role in providing health care services in the western region of Saudi Arabia; it acts as a safety net health care system. However, this role is resulting in a major ED crowding challenge that might 
potentially impact patients' safety and the quality of care. Fortunately, KAUH ED is capable of managing all true emergencies in an appropriate and timely manner despite its crowding crisis. Future efforts should be directed toward diverting the use of KAUH ED by lower acuity cases to the appropriate channels.

\section{Conflict of Interest}

The author has no conflict of interest.

\section{Disclosure}

The author did not receive any commercial or financial support for this study. The author has no financial interest in any of the products, devices, or drugs mentioned in this article.

\section{Ethical Approval}

Not required.

\section{References}

[1] Pines JM, Hilton JA, Weber EJ, Alkemade AJ, Al Shabanah $H$, Anderson PD, Bernhard M, Bertini A, Gries A, Ferrandiz S, Kumar VA, Harjola VP, Hogan B, Madsen B, Mason S, Ohlén G, Rainer T, Rathlev N, Revue E, Richardson D, Sattarian M, Schull MJ. International perspectives on emergency department crowding. Acad Emerg Med 2011; 18(12): 1358-1370.

[2] Bernstein SL, Aronsky D, Duseja R, Epstein S, Handel D, Hwang U, McCarthy M, John McConnell K, Pines JM, Rathlev N, Schafermeyer R, Zwemer F, Schull M, Asplin BRThe effect of emergency department crowding on clinically oriented outcomes. Acad Emerg Med 2009; 16: 1-10.

[3] Sun BC, Hsia RY, Weiss RE, Zingmond D, Liang LJ, Han W, McCreath $H$, Asch SM. Effect of emergency department crowding on outcomes of admitted patients. Ann Emerg Med 2013; 61(6): 605-611.

[4] Singer AJ, Thode HC Jr, Viccellio P, Pines JM. The association between length of emergency department boarding and mortality. Acad Emerg Med 2011; 18(12): 1324-1329.

[5] Pines JM, lyer S, Disbot M, Hollander JE, Shofer FS, Datner EM. The effect of emergency department crowding on patient satisfaction for admitted patients. Acad Emerg Med. 2008; 15(9): 825-831.

[6] Gaieski DF, Mikkelsen ME, Band RA, Pines JM, Massone R, Furia FF, Shofer FS, Goyal M. Impact of time to antibiotics on survival in patients with severe sepsis or septic shock in whom early goal-directed therapy was initiated in the emergency department. Crit Care Med 2010; 38(4): 10451053.
[7] Asplin BR, Magid DJ, Rhodes KV, Solberg LI, Lurie N, Camargo CA. A conceptual model of emergency department crowding. Ann Emerg Med 2003; 42(2): 173-180.

[8] Rui P, Kang K. National Hospital Ambulatory Medical Care Survey: 2014 Emergency Department Summary Tables. Available from: <http://www.cdc.gov/nchs/data/ahcd/ nhamcs_emergency/2014_ed_web_tables.pdf.> 
خصائص زيارات قسم طب الطوارئ في مستشفى جامعة الملك عبدالعزيز. تحليل سنة واحدة.

$$
\begin{aligned}
& \text { جميل طلال جميل أبو العينين }
\end{aligned}
$$

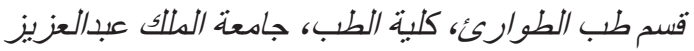

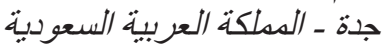

$$
\begin{aligned}
& \text { قسم طب الطوارئ، مستشفى جامعة الملك عبدالعزئية }
\end{aligned}
$$

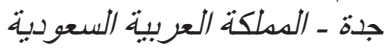

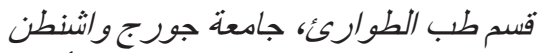

$$
\begin{aligned}
& \text { واشنطن دي سي ـ الولايات المتحدة الأمريكية }
\end{aligned}
$$

المستخلص. تهدف الدر اسة إلى تحديد معدل الزيار ات وتحليل المعلومات التشغيلية لقسم طب الطوارئ بمستشفى جامعة

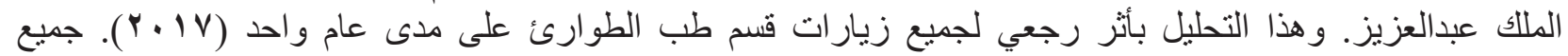

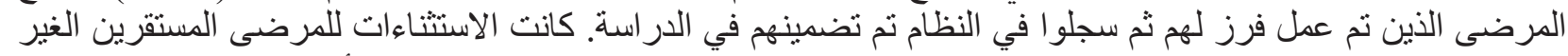

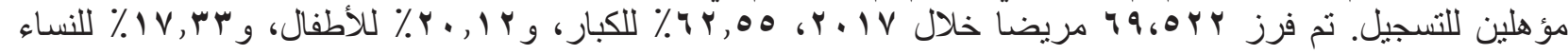

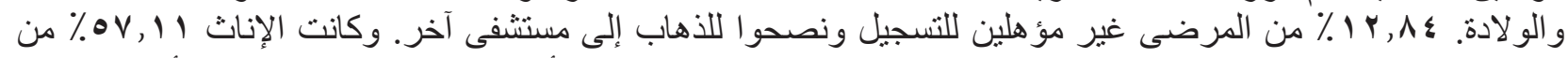

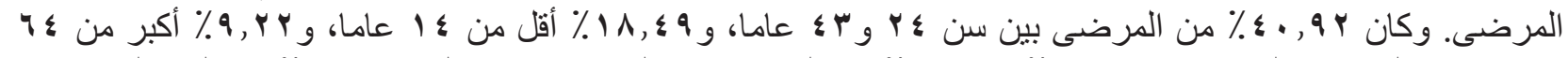

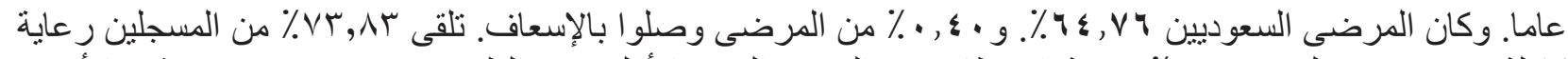

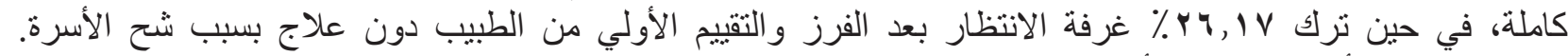

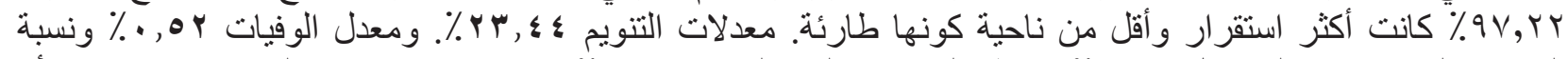

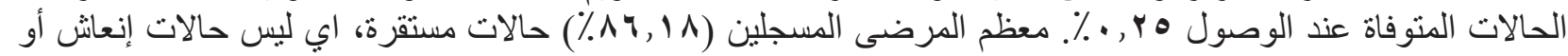

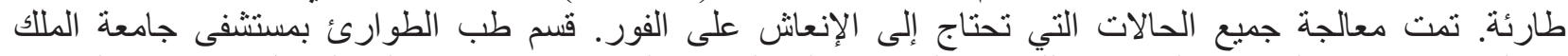

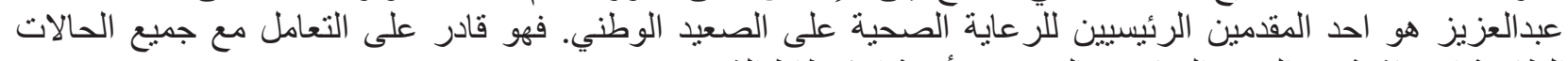

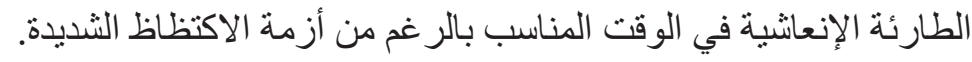

